\title{
Antibacterial activity of plant extracts against Listeria monocytogenes isolated from ready-to-eat salads
}

\author{
É. György ${ }^{1}$
}

e-mail: gyorgyeva@uni.sapientia.ro

\author{
É. Laslo ${ }^{2}$ \\ e-mail: lasloeva@uni.sapientia.ro
}

\section{E. Csató ${ }^{1}$}

e-mail: erzsebetcsato@yahoo.com

\begin{abstract}
${ }^{1}$ Sapientia Hungarian University of Transylvania (Cluj-Napoca, Romania), Faculty of Economics, Socio-Human Sciences and Engineering, Department of Food Science, RO-530104 Miercurea Ciuc, 1 Libertăţii Sq. ${ }^{2}$ Sapientia Hungarian University of Transylvania (Cluj-Napoca, Romania), Faculty of Economics, Socio-Human Sciences and Engineering, Department of Bioengineering, RO-530104 Miercurea Ciuc, 1 Libertăţii Sq.
\end{abstract}

\begin{abstract}
Ready-to-eat salads are becoming more and more popular. However, due to their ingredients, they represent a suitable growth environment for different microbes. In the prevention of foodborne diseases, hygienic food preparation and appropriate storage conditions are very important. During this study, ten different ready-to-eat salads were analysed for the presence of Listeria monocytogenes. Five different selective agar mediums were used for the enumeration and isolation of Listeria monocytogenes. The isolated bacterial strains were subjected to morphological and biochemical confirmation tests. The antibacterial effects of five different freshly squeezed vegetable juices (carrots, celery, beets, horseradish, and onions) and of five essential oils (dill, thyme, oregano, lemongrass, and sage) were determined against Listeria monocytogenes, Listeria innocua, and L. monocytogenes strains isolated from
\end{abstract}

Keywords and phrases: ready-to-eat salad, fresh vegetable juices, essential oils 
ready-to-eat salads. Based on the results obtained from fresh vegetable juices, carrot juice exerted the highest antibacterial effect, while the others showed no or slight inhibitory effect (horseradish, beets, onions) against Listeria species. Among the essential oils, thyme, lemongrass, and oregano showed the strongest antibacterial effect against the studied Listeria species.

\section{Introduction}

The genus Listeria has 17 species; six among them show high genetic relatedness: L. monocytogenes, L. ivanovii, L. seeligeri, L. welshimeri, L. innocua, and L. marthii. L. monocytogenes is pathogenic to humans and ruminants. On rare occasions, L. ivanovii, which is pathogenic to ruminants, may infect humans, causing foodborne outbreaks (Bhunia, 2018).

L. monocytogenes is a causative agent for listeriosis disease, affecting primarily the immunocompromised populations (pregnant women, neonates, human immunodeficiency virus-infected patients, and organ transplant recipients); on rare occasions, it causes gastroenteritis in immunocompetent persons (Bhunia, 2018). These bacteria can invade intestinal epithelial cells and multiply in phagocytic cells. They are able to enter the bloodstream, causing septicaemia or meningitis; additionally, the infection of the foetus may lead to miscarriage. The severity of listeriosis is associated with a high mortality rate, reaching 25\%-30\% (Deák, 2006).

L. monocytogenes is widely distributed in nature, can grow at $3-4{ }^{\circ} \mathrm{C}$, and is able to survive freezing and drying temperatures in food. It enters the body through different foods, unwashed vegetables, contaminated milk, dairy products, and meat (Deák, 2006). Examination of the prevalence of these bacteria in fresh agricultural products revealed that L. monocytogenes was detected in the case of cucumbers, cabbage, carrots, tomatoes, and lettuce, while in the case of fruits it was detected in sliced apples and peaches. Thus, freshly consumed fruits and vegetables can be associated with human listeriosis (Grumezescu \& Holban, 2018). The ability of L. monocytogenes to survive under extreme conditions and to form a biofilm is a food safety issue. Removal of these bacteria from food processing industries presents difficulties. Because L. monocytogenes forms part of the natural gut microbiota, its presence in slaughterhouses, in meat-processing factories, or in the retail trade can lead to cross-contamination. The risk of food contamination can be reduced effectively by the application of workers' hygiene and sanitation practices in food preparation plants and also by knowledge about how bacteria spread (Kurpas 
et al., 2018). Meat and poultry products are the main carriers of L. monocytogenes. Among these products, the most common source are ready-to-eat (RTE) products (Bhunia, 2018).

RTE foods are food products that have undergone different preparation steps and can be used without any additional bactericidal treatment such as reheating. The production of RTE sandwiches, salads, and meats involves human handling (cutting or slicing), which can lead to cross-contamination. Because of the increasing demand and consumption of these types of foods and the fact that they are not further processed, the microbiological risks to consumers have also risen. The number of diseases transmitted by certain allochthonous microbes in RTE foods is on the rise; in some cases, food infection or poisoning may have fatal consequences. The genetically encoded survival mechanism of L. monocytogenes against a number of preservation conditions (heating, cooling, salting, $\mathrm{pH}$ reduction) and the high mortality rate of listeriosis highlight its importance in RTE foods. Antibiotic-resistant Listeria species have been detected in raw and RTE foods. Listeria monocytogenes isolates were resistant to ampicillin, penicillin, tetracycline, rifampicin, and sulphamethoxazole trimethoprim (Marian et al., 2012).

The ecological and physiological characteristics of $L$. monocytogenes allow its colonization of food environments, and so it is able to grow and multiply during processing and storage. Their stress resistance is due to their biofilmforming ability, and the formation of persistent cells increases their ability to survive under environmental stress conditions (Buchanan et al., 2017).

The food industry currently needs innovative processing technologies and preservation methods to meet consumer demands for fresher and safer RTE products. For these purposes, the use of natural antimicrobial compounds is an alternative method. The antimicrobial and antioxidant properties of plant essential oils, phenolic and related compounds are known, and it is important to highlight their potential use in the active packaging. Antimicrobial-based food packaging systems are based on two principals: the antimicrobial agent migrates into the food and the antimicrobial agent is incorporated into the packaging material (Siddiqui \& Rahman, 2015). From the essential oils, for example, oregano and thyme essential oil can be used as natural preservation methods due to their significant antibacterial properties (Bhagat et al., 2016). Clove essential oil, whose main ingredient is eugenol, affects cell structure and causes irreversible damage to the cell membrane as well as leakage of three biological macromolecules (protein, ATP, and DNA) and may lead to the decreased activity of two intracellular enzymes ( $\beta$-galactosidase and AKP). Clove oil affects the respiratory metabolism of Listeria monocytogenes, reduces the 
activity of enzymes involved in the citrate cycle (isocitrate dehydrogenase, citrate synthase, and $\alpha$-ketoglutarate), and eugenol alters the structure of DNA by forming eugenol-DNA chimeras. The minimal inhibitory concentration of clove essential oil on Listeria monocytogenes was $0.5 \mathrm{mg} / \mathrm{ml}$, resulting in a 95.82\% reduction after 4 hours and $99.99 \%$ after 8 hours (Cui et al., 2018).

Cranberry juice concentrate was used in the preservation of RTE, which did not affect the organoleptic properties of red pepper and exhibited antibacterial activity against Escherichia coli O157: H7, Listeria monocytogenes, and Salmonella typhimurium (Harich et al., 2017). Lemon essential oil showed good results in reducing the number of $L$. monocytogenes in fruit-based salads (Hwang \& Huang, 2010). The aim of the present study is to determine the antimicrobial effect of five different freshly squeezed vegetable juices and of five essential oils against Listeria monocytogenes, Listeria innocua, and $L$. monocytogenes strains isolated from RTE salads on five different selective agar media.

\section{Materials and methods}

During our work, ten different RTE salads (Table 1) were analysed for the presence of Listeria monocytogenes.

Table 1. Ingredients of RTE salads examined for Listeria monocytogenes

\begin{tabular}{cl}
\hline Sample & \multicolumn{1}{c}{ Ingredients } \\
\hline 1 & lettuce, cucumber, tomato, onion, olive, pizza crust \\
2 & cucumber, tomato, onion, olive, Feta-like cheese - Telemea, red paprika \\
3 & lettuce, cucumber, tomato, onion, tuna, egg, lemon, corn, olive, pizza crust \\
4 & lettuce, tomato, chicken meat, peas, corn, olive \\
5 & olive, Feta-like cheese - Telemea, tomato, red paprika, cucumber, onion, \\
6 & lettuce, oil \\
7 & lettuce, cucumber, chicken meat, cottage cheese, corn, tomato, carrot, \\
8 & red cabbage \\
9 & mushrooms, olive, lettuce, cheese, carrot, tomato, red cabbage \\
10 & cabbage, onion, tomato, corn, carrot, lettuce \\
\hline
\end{tabular}


From the stock suspension (10 g sample and $90 \mathrm{ml}$ physiological solution), prepared as a first step, 1-1 ml was spread onto five different selective agar media for the enumeration and isolation of Listeria monocytogenes (Listeria mono Differential Agar, Listeria Oxford Medium Base, Listeria mono Differential Agar Base, Listeria Identification Agar Base (Palcam), ChromoBioßListeria Plus Base). After incubation, colonies with a morphology typical of Listeria spp. were isolated and streak plates were made. The isolated bacterial strains were subjected to confirmation and biochemical tests. During the microscopic morphological observations, the cell shape, motility, and Gram type with 3\% $\mathrm{KOH}$ test of the bacterial isolates were determined. The selected Listeria isolates were subjected to catalase test, indole test, hydrogen sulphide production, and carbohydrate fermentation test on TSI medium. Also, the growth capacity of bacterial isolates in the presence of $16 \% \mathrm{NaCl}$ was determined.

The next step of the research was the determination of the antibacterial effect of 5 different freshly squeezed vegetable juices (carrots, celery, beets, horseradish, onions) and 5 essential oils (dill, thyme, oregano, lemongrass, sage) against Listeria monocytogenes, Listeria innocua strains, and L. monocytogenes isolates from RTE salads with agar diffusion method. Listeria monocytogenes, and Listeria innocua were used for positive control.

Commercially available vegetables and essential oils used for the study were purchased from a local supermarket. The selection of the essential oils took into account that they come from herbs with culinary applications. In a sterilized Petri dish, the solidified Nutrient Agar and Listeria Enrichment Agar mediums were inoculated on the surface with a $0.1 \mathrm{ml}$ suspension of the tested bacterial strains and isolates $\left(10^{8} \mathrm{CFU} / \mathrm{ml}\right)$. At the centre of all of the inoculated media, an $8 \mathrm{~mm}$ diameter hole was cut with the help of a sterile test-tube. In this hole, $0.2 \mathrm{ml}$ of vegetable juice and essential oil was dropped. The incubation was carried out at the temperature of $37^{\circ} \mathrm{C}$ for 24 hours. Following incubation, the inhibition zones were measured in $\mathrm{mm}$.

\section{$3 \quad$ Results and discussions}

Based on the results, the highest number of Listeria monocytogenes was detected in samples $5,7,8$, and 10, whereas the lowest occurrence of these bacteria was detected in sample 6 (Table 2 ). 
Table 2. Occurrence of Listeria monocytogenes in analysed samples on the different selective mediums

\begin{tabular}{|c|c|c|c|c|c|}
\hline $\begin{array}{c}\text { Ready- } \\
\text { to-eat } \\
\text { salad } \\
\text { samples }\end{array}$ & $\begin{array}{c}\text { Listeria } \\
\text { mono } \\
\text { Differential } \\
\text { Agar } \\
\text { CFU /g }\end{array}$ & $\begin{array}{l}\text { Listeria } \\
\text { Oxford } \\
\text { Medium } \\
\text { Base } \\
\text { CFU/g }\end{array}$ & $\begin{array}{c}\text { Listeria } \\
\text { mono } \\
\text { Differential } \\
\text { Agar Base } \\
\text { CFU/g }\end{array}$ & $\begin{array}{c}\text { Listeria } \\
\text { Identification } \\
\text { Agar Base } \\
\text { (PALCAM) } \\
\text { CFU/g }\end{array}$ & $\begin{array}{c}\text { ChromoBio } \AA \\
\text { Listeria } \\
\text { Plus Base } \\
\text { CFU /g }\end{array}$ \\
\hline 1 & $5.7 \cdot 10^{2}$ & $1.51 \cdot 10^{3}$ & $6.9 \cdot 10^{2}$ & $2.8 \cdot 10^{2}$ & $3 \cdot 10$ \\
\hline 2 & $1.4 \cdot 10^{2}$ & $3.2 \cdot 10^{2}$ & $8.6 \cdot 10^{2}$ & $9.3 \cdot 10^{2}$ & $2 \cdot 10$ \\
\hline 3 & $1.16 \cdot 10^{3}$ & $9.5 \cdot 10^{2}$ & $8.5 \cdot 10^{2}$ & $2.2 \cdot 10^{2}$ & $1.7 \cdot 10^{2}$ \\
\hline 4 & $4.54 \cdot 10^{3}$ & $6 \cdot 10$ & $5.3 \cdot 10^{2}$ & $3.73 \cdot 10^{3}$ & $<10$ \\
\hline 5 & $4.67 \cdot 10^{3}$ & $3.66 \cdot 10^{3}$ & $3.95 \cdot 10^{3}$ & $4.52 \cdot 10^{3}$ & $<10$ \\
\hline 6 & $<10$ & $1 \cdot 10$ & $2.2 \cdot 10^{2}$ & $1.5 \cdot 10^{2}$ & $4 \cdot 10$ \\
\hline 7 & $4.03 \cdot 10^{3}$ & $3.02 \cdot 10^{3}$ & $5.46 \cdot 10^{3}$ & $4.55 \cdot 10^{3}$ & $3 \cdot 10$ \\
\hline 8 & $3.29 \cdot 10^{3}$ & $1.05 \cdot 10^{3}$ & $6.43 \cdot 10^{3}$ & $6.12 \cdot 10^{3}$ & $4 \cdot 10$ \\
\hline 9 & $1.89 \cdot 10^{3}$ & $3 \cdot 10$ & $1.94 \cdot 10^{3}$ & $2.21 \cdot 10^{3}$ & $7 \cdot 10$ \\
\hline 10 & $6.17 \cdot 10^{3}$ & $6.77 \cdot 10^{3}$ & $6.39 \cdot 10^{3}$ & $6.23 \cdot 10^{3}$ & $1 \cdot 10$ \\
\hline
\end{tabular}

From the typical L. monocytogenes colonies, developed on the selective agar mediums, 56 pure cultures were obtained. According to the results of morphological confirmation tests, 11 Listeria isolates were selected. These isolates are Gram-positive, motile rod-shaped bacteria, which are the most common characteristics of Listeria species. According to the results of biochemical confirmation tests, 10 out of 11 isolates possessed typical characteristics of Listeria such as glucose utilization, non-indole- and non-hydrogen sulphide production, and the ability to grow in the presence of $16 \% \mathrm{NaCl}$ (Table 3).

Most bacterial isolates with typical characteristics of Listeria monocytogenes were isolated from Listeria Oxford Medium Base, which was found to be a highly selective medium. Regarding selectivity, this was followed by Listeria Identification Agar Base (PALCAM) and, finally, by Listeria mono Differential Agar Base.

Food-borne listeriosis has been associated with the consumption of dairy products, seafood, meat products, fresh vegetables and fruits, and RTE foods. Among RTE foods, raw foods by non-thermal processing (salads, vegetables, fruits, dairy products) pose an increased health risk to consumers. For foodproducers, Listeria monocytogenes represents a challenge in this context and a priority because it is widely distributed in nature and is able to grow at low temperatures (Ziegler et al., 2019). Because of the changes in lifestyle, RTE foods are still prominent. Consuming these foods raw or minimally processed, L. monocytogenes may be present due to their high survival rate, psychrophilic 
character, ability to form biofilm in food-processing equipment, and resistance to most disinfectants (Szymczak et al., 2020). Regulation of L. monocytogenes in RTE foods differs from country to country, ranging from minimum level as zero tolerance (0 CFU in $25 \mathrm{~g}$ ) for all RTE foods to maximum level (100 $\mathrm{CFU} / \mathrm{g}$ ) for foods which do not promote growth (Dong et al., 2021).

Table 3. Biochemical confirmation test results of Listeria isolates

\begin{tabular}{lcccc}
\hline $\begin{array}{c}\text { Bacterial } \\
\text { isolate }\end{array}$ & $\begin{array}{c}\text { Glucose } \\
\text { utilization }\end{array}$ & $\begin{array}{c}\text { Hydrogen } \\
\text { sulphide } \\
\text { production }\end{array}$ & $\begin{array}{c}\text { Indole } \\
\text { production }\end{array}$ & $\begin{array}{c}\text { Growth in } \\
\text { the presence } \\
\text { of 16\% NaCl }\end{array}$ \\
\hline Li 1 LOM & + & - & - & + \\
Li 2 LMDAB & + & - & - & + \\
Li 3-1 LOM & + & - & - & + \\
Li 3-2 LOM & + & - & - & + \\
Li 4 LOM & + & - & - & + \\
Li 7 LOM & + & - & - & + \\
Li 9-1 PA & + & - & - & + \\
Li 9-2 PA & + & - & - & + \\
Li 9-1 LOM & + & - & - & + \\
Li 9-2 LOM & - & - & - & + \\
Li 10 PA & + & - & - & + \\
\hline
\end{tabular}

Notes: Li: Listeria; 1, 2, 3, 4, 7, 9, 10: RTE salad sample numbers; LOM: Listeria Oxford Medium Base; LMDAB: Listeria mono Differential Agar Base; PA: Listeria Identification Agar Base (PALCAM)

Analysing the ingredients of various salads, Listeria sp. was detected in marinated and smoked fish, cabbage, carrots, and dairy products (e.g. Feta cheese) (Szymczak et al., 2020). In an outbreak of listeria infection in a hospital, as a vehicle for $L$. monocytogenes contamination celery, an ingredient of chicken salad, was mentioned (Sahu et al., 2017). Different factors significantly influence the growth of L. monocytogenes, such as the food matrix, storage temperature, or storage time. Reduction of the storage temperature in the market to $5{ }^{\circ} \mathrm{C}$ coupled with the product's shelf life could contribute to reducing the risk of L. monocytogenes in RTE salads (Ziegler et al., 2019). The duration of the LAG phase can be influenced by the $\mathrm{pH}$ value of mayonnaise, for example, in seafood salad; however, the most important factor influencing the rate of reproduction is storage temperature (Skalina \& Nikolajeva, 2010). The presence of low levels of $L$. monocytogenes in sample 6 may be associated with the sample ingredients. This RTE salad contained less raw ingredients and contained mayonnaise, pickled cucumber, toasted bread cubes, 
and cooked chicken breast.

Based on the results of the antimicrobial activity of freshly squeezed vegetable juice, celery had no antibacterial effect against the tested Listeria species. Beet juice had no inhibitory effect on the growth of L. monocytogenes and L. innocua. In the case of Listeria isolates, a small zone of inhibition could be observed (Table 4).

White onion juice showed a slight antibacterial effect against five Listeria isolates; no zone of inhibition was found in the case of the other tested bacteria. Horseradish juice exerted slight inhibition on most Listeria isolates, but no inhibition was detected against L. monocytogenes and L. innocua. According to numerous studies, carrot juice possesses an antimicrobial effect against $L$. monocytogenes and other Listeria species (Deák, 2006). Based on our experiments, an inhibition zone was detected against L. monocytogenes, L. innocua, and all tested Listeria isolates.

Among the studied essential oils, the strongest antimicrobial effect was shown by thyme and lemongrass, followed by oregano (Table 5). Sage essential oil exhibited a small inhibition zone, but some Listeria isolates originated from fresh salads were more sensitive than laboratory strains. Dill essential oil did not inhibit L. monocytogenes, and in the case of $L$. innocua a small zone of inhibition was found $(1.50 \pm 0.52)$. Among the bacterial isolates, there were susceptible strains where complete inhibition also occurred.

Thymus vulgaris essential oil presented inhibitory activity against pathogenic bacteria $S$. aureus and L. monocytogenes, which are often associated with fresh and low-ripened cheese (Julliane de Carvalho et al., 2015). In particular, cinnamon and oregano showed strong activity against seven out of ten L. monocytogenes strains although they showed a lower efficacy against Salmonella strains (Mazzarrino et al., 2015). Melissa officinalis has an antimicrobial effect against Bacillus subtilis, Clostridium botulinum, Escherichia coli, Listeria monocytogenes, Salmonella typhimurium, and Staphylococcus aureus (Tajkarimi et al., 2010). The essential oil of Salvia officinalis showed strong bactericidal and bacteriostatic effects against both Gram-positive and Gram-negative bacteria. Among Gram-positive pathogens, Bacillus cereus, Bacillus megaterium, Bacillus subtilis, Enterococcus faecalis, Listeria monocytogenes, and Staphylococcus epidermidis show high sensitivity to S. officinalis (Ghorbani \& Esmaeilizadeh, 2017). Essential oils of Apium graveolens showed antimicrobial activity against Saccharomyces cerevisiae, Listeria monocytogenes, Staphylococcus aureus, Salmonella sp., and Escherichia coli (Gupta et al., 2012). 


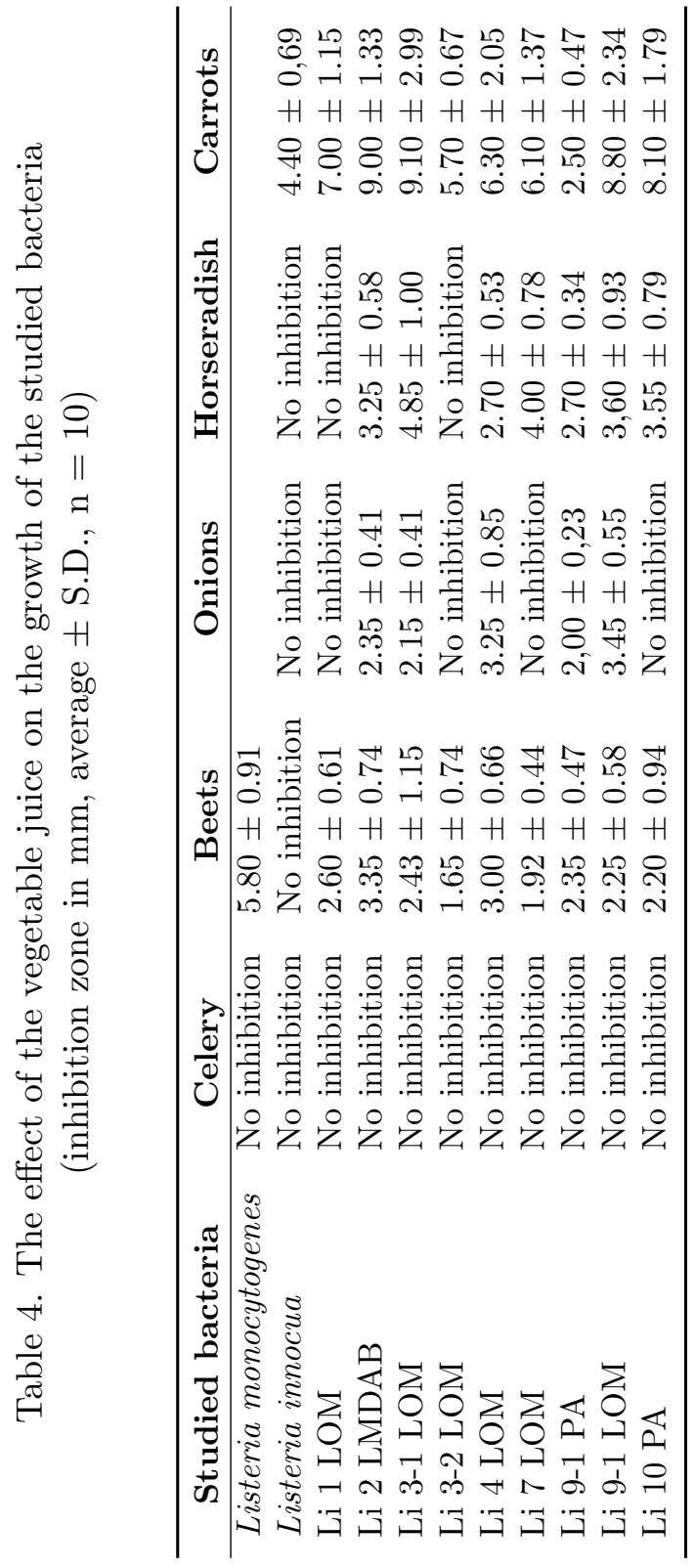




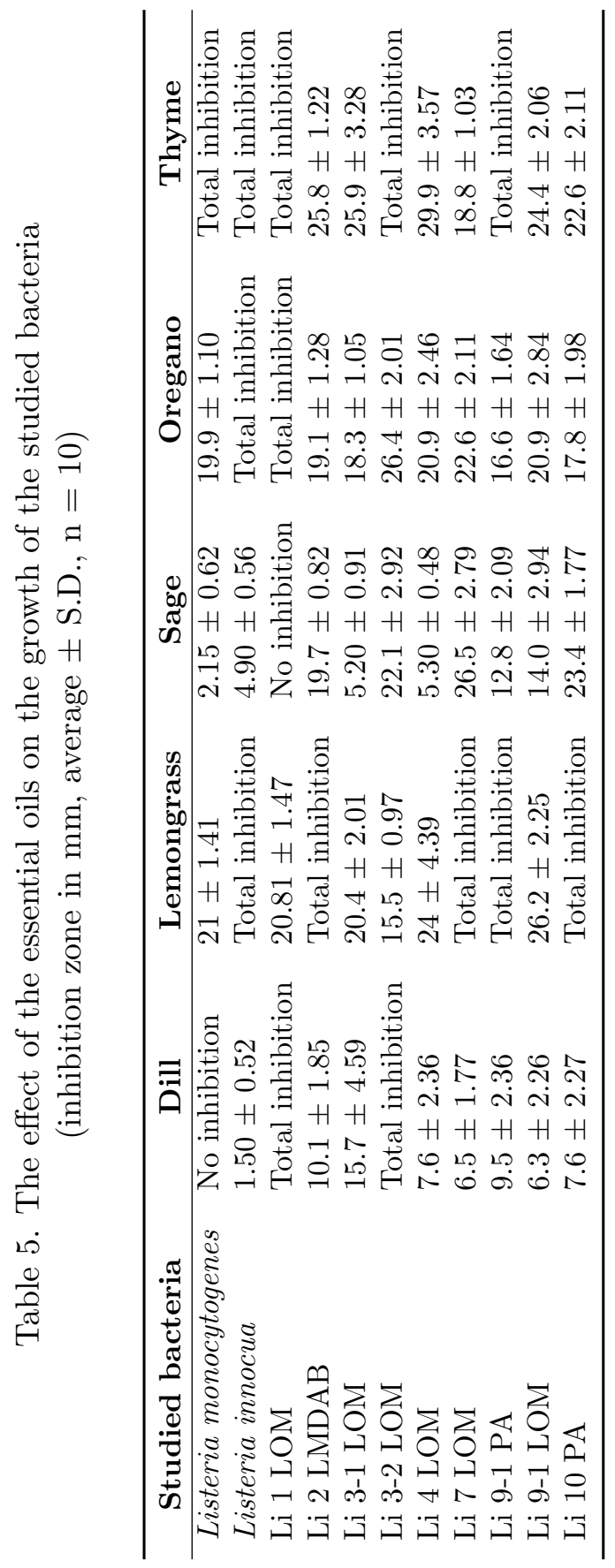




\section{Conclusions}

As ready-to-eat salads contain many raw ingredients, the presence of Listeria monocytogenes needs to be taken into account. Therefore, it is very important to maintain hygiene during the processing of raw materials and manufacture and to ensure adequate storage conditions throughout the shelf life. Among the selective media used in our investigation, the highly selective medium for the isolation of Listeria monocytogenes was found to be the Listeria Oxford Medium Base. Results from our study demonstrated that carrot juice exerted the highest antibacterial effect on the Listeria species. Among the essential oils, thyme, lemongrass, and oregano showed the strongest antimicrobial effect against L. monocytogenes, L. innocua, and Listeria isolates originated from salads. The use of natural antimicrobials (fresh vegetable juices or essential oils), which can also be used for gastronomic purposes, can contribute to the production of safe and healthy food.

\section{References}

[1] Bhagat, A., Caruso, G., Micali, M., Parisi, S., Foods of non-animal origin. Chemistry, technology, inspection procedures. Springer. (2016).

[2] Bhunia, A. K., Foodborne microbial pathogens. Mechanisms and pathogenesis. Springer. (2018).

[3] Buchanan, R. L., Gorris, L. G. M., Hayman, M. M., Jackson, T. C., Whiting, R. C., A review of Listeria monocytogenes. An update on outbreaks, virulence, dose-response, ecology, and risk assessments. Food Control, 75. (2017) 1-13.

[4] Cui, H., Zhang, C., Li, C., Lin, L., Antimicrobial mechanism of clove oil on Listeria monocytogenes. Food Control, 94. (2018) 140-146.

[5] de Carvolho, R. J., de Souza, G. T., Honório, V. G., de Sousa, J. P., da Conceiçăo, M. L., Maganani, M., de Sousa, E. L., Comparative inhibitory effects of Thymus vulgaris L. essential oil against Staphylococcus aureus, Listeria monocytogenes and mesophilic starter co-culture in cheese-mimicking models. Food Microbiology, 52. (2015) 59-65.

[6] Deák, T., Élelmiszer-mikrobiológia. Mezőgazda Kiadó, Budapest. (2006). 
[7] Dong, A., Malo, A., Leong, M., Ho, V. T. T., Turner, M. S., Control of Listeria monocytogenes on ready-to-eat ham and fresh cut iceberg lettuce using a nisin containing Lactococcus lactis fermentate. Food Control, 119. (2021) 104420.

[8] Ghorbani, A., Esmaeilizadeh, M., Pharmacological properties of Salvia officinalis and its components. Journal of Traditional and Complementary Medicine, 7. (2017) 433-440.

[9] Grumezescu, A. M., Holban, A. M., Food safety and preservation. Modern biological approaches to improving consumer health. Academic Press. (2018).

[10] Gupta, R., Anwer, M. M., Sharma, Y. K., Dill. In: Peter, K. V., Handbook of herbs and spices. Woodhead Publishing. (2002).

[11] Harich, M., Maherani, B., Salmieri, S., Lacroix, M., Antibacterial activity of cranberry juice concentrate on freshness and sensory quality of ready to eat (RTE) foods. Food Control, 75. (2017) 134-144.

[12] Hwang, A., Huang, L., Ready-to-eat foods: Microbial concerns and control measures. CRC Press. (2010).

[13] Kurpas, M., Wieczorek, K., Osek, J., Ready-to-eat meat products as a source of Listeria monocytogenes. Journal of Veterinary Research, 62. (2018) 49-55.

[14] Marian, M. N., Aminah, S. M. S., Zuraini, M. I., Son, R., Maimunah, M., Lee, H. Y., Wong, W. C., Elexon, L., MPN-PCR detection and antimicrobial resistance of Listeria monocytogenes isolated from raw and ready-to-eat foods in Malaysia. Food Control, 28. (2012) 309-312.

[15] Mazzarrino, G., Paparella, A., Chaves-López, C., Faberi, A., Sergi, M., Sigismondi, C., Compagnone, D., Serio, A., Salmonella enterica and Listeria monocytogenes inactivation dynamics after treatment with selected essential oils. Food Control, 50. (2015) 794-803.

[16] Sahu, S. N., Kim, B., Ferguson, M. S., Zink, D. L., Datta, A. R., Growth potential of Listeria monocytogenes in artificially contaminated celery and chicken salad. Food Control, 73. (2017) 1229-1236.

[17] Siddiqui, M. W., Rahman, M. S., Minimally processed foods technologies for safety, quality, and convenience. Springer. (2015). 
[18] Skalina, L., Nikolajeva, V., Growth potential of Listeria monocytogenes strains in mixed ready-to-eat salads. International Journal of Food Microbiology, 144. (2010) 317-321.

[19] Szymczaka, B., Szymczakb, M., Trafiałekc, J., Prevalence of Listeria species and L. monocytogenes in ready-to-eat foods in the West Pomeranian region of Poland: Correlations between the contamination level, serogroups ingredients, and producers. Food Microbiology, 91. (2020) 103532.

[20] Tajkarimi, M. M., Ibrahim, S. A., Cliver, D. O., Antimicrobial herb and spice compounds in food. Food Control, 21. (2010) 1199-1218.

[21] Ziegler, M., Kent, D., Stephan, R., Guldimann, C., Growth potential of Listeria monocytogenes in twelve different types of RTE salads: Impact of food matrix, storage temperature and storage time. International Journal of Food Microbiology, 296. (2019) 83-92. 